\title{
Looking Forward to the First Impact Factor of Archives of Plastic Surgery
}

\author{
Tai Suk Roh \\ Co-Editor, Archives of Plastic Surgery \\ Department of Plastic and Reconstructive Surgery, Gangnam Severance Hospital, Yonsei University College \\ of Medicine, Seoul, Korea
}

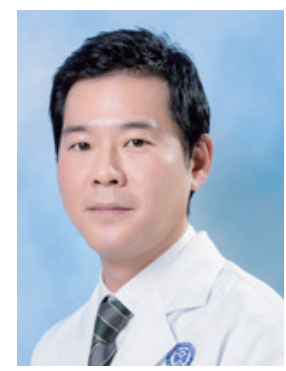

Since the rebirth of the Journal of the Korean Society of Plastic and Reconstructive Surgeons as Archives of Plastic Surgery (APS), three years and 11 months have passed. During this time, APS continues to improve the quality of its articles, expand its international diversity, and increase the accessibility of its articles, all toward the goal of being a leading journal of plastic surgery in the AsiaPacific region.

Among the goals of APS, I believe that the most essential one for its development is continuing to increase the quality of articles. If we publish articles of high impact and originality, other researchers and clinicians will read and cite those articles, and the reputation of APS will continue to grow. New authors will then want to submit their core studies to APS and they will be read and cited again and again. This virtuous cycle is an ideal model for all scientific journals, including APS. Breaking into this cycle will continue to require tremendous focus, time, and effort from all the editorial staff.

Citation is a critical factor for determining the significance of each article and journal. Citation is also important because it can be quantified as a simple figure which is easily recognized and compared with other articles or journals. As readers may know, the impact factor is the metric for citation of specific journals determined by the Institute for Scientific Information. What then is the definition of impact factor? A journal's impact factor is based on two elements: the numerator, which is the number of citations in the current year to items published in the previous two years, and the denominator, which is the number of substantive articles and reviews published in the same two years [1]. This means that the impact factor reflects the immediate popularity of published articles in a specific journal by colleagues work- ing simultaneously in the same academic field.

Of course, the impact factor has received its share of criticism. One concern is that the impact factor has a weak correlation with scientific significance; it only reflects 'recognition' of the specific subject in a short period [2]. Some have argued that journals addressing a broad spectrum of topics may have a greater potential for reaching a high impact factor than specialized journals in narrow fields because submitted manuscripts may tend to undergo more competition for publication in less specialized journals [3].

However, we cannot deny that the impact factor is an accepted measure for assessing the quality of articles or journals all over the world. This number is used by promotion committees in universities and research institutes, for evaluation of research grant proposals, and to assess the academic achievements of researchers and clinicians. Even a journal's reputation and ranking is determined by this number. It is not difficult to find journals that advertise their high impact factors.

APS has just met the minimum requirements for calculating impact factor because the numerator and denominator are determined 3 years from the beginning of the title's publication. We expect our first impact factor to be released soon. We know the field of plastic surgery is very competitive and that journals with good reputations have already been publishing for several decades. Gaining a high ranking among plastic surgery journals as measured by impact factor will not be easy in the near future.

Nevertheless, we should strive to grow our reputation as represented by the impact factor. As noted previously, increasing the quality of articles will be a pivotal factor for entering a 'virtuous cycle' of growth. For this, we will encourage domestic plastic 
surgeons to submit their sophisticated work to APS, while inviting renowned foreign authors to submit their achievements as original or review articles. We will also aim to increase the quality of reviews because reviewers' comments have a great influence on authors and can improve the quality of submitted manuscripts. We will continue to systematically upgrade our submission and review system for easy accessibility and the availability of various multimedia resources.

We hope that our dedication and investment is not in vain and will bear fruit, resulting in our becoming the leading journal in the Asia-Pacific region and being indexed in Science Citation Index Expanded in the foreseeable future. We also hope APS can contribute to the global development of plastic surgery in this process [4].

\section{REFERENCES}

1. Garfield E. The history and meaning of the journal impact factor. JAMA 2006;295:90-3.

2. Impact versus Significance in scientific publishing. Eur J Immunol 2015;45:i-ii.

3. Rohrich RJ, Sullivan D. The role of the journal impact factor: choosing the optimal source of peer-reviewed plastic surgery information. Plast Reconstr Surg 2006;117:2495-8.

4. Kim YH. The current position of Archives of Plastic Surgery and its future. Arch Plast Surg 2015;42:387-90.

Correspondence: Tai Suk Roh

Department of Plastic and Reconstructive Surgery, Gangnam Severance Hospital, Yonsei University

College of Medicine, 211 Eonju-ro, Gangnam-gu, Seoul 06273, Korea

Tel: +82-2-2019-3422, Fax: +82-2-2019-3422, E-mail: ROHTS@yuhs.a

No potential conflict of interest relevant to this article was reported.

Received: 16 Oct $2015 \bullet$ Revised: 16 Oct $2015 \bullet$ Accepted: 16 Oct 2015

pISSN: 2234-6163 • elSSN: 2234-6171

http://dx.doi.org/10.5999/aps.2015.42.6.675 • Arch Plast Surg 2015;42:675-676 